\title{
- \\ of Science and Technology Studies
}

\section{ABOUT THE COVER ARTIST}

Helena Cleeve

By Helena Cleeve

The front cover features an illustration made by Helena Cleeve. The illustration, which was created particularly for this special issue seeks to outline how care practices may simultaneously enact diverging and contradictory realities. Care may be reparative, creative and transformative but also constricting, selective, and derivative.

Helena Cleeve is currently employed as a postdoctoral researcher at Karolinska Institutet in Sweden. While Cleeve holds a PhD in medical science, also from Karolinska Institutet, her background is not in healthcare, but within the field of design. She holds as a BFA in industrial design from Lund University in Sweden, and an MFA in Transdisciplinary Design from Parsons the New School for Design in New York, the United States. Cleeve's interest in the visual and material is noticeable in her research as she combines healthcare sciences, care studies in Science and Technology Studies with visuals research methods. She recently defended her PhD thesis "Mundane mattering: how materialities come to matter in everyday life in dementia care units and in end of life care", which discusses the significance of seemingly mundane things in nursing homes and in palliative care settings. The research is based on interviews, workshops and ethnographic fieldwork but it also exemplifies how illustrations and drawings can be used to study issues concerning materialities. The thesis shows that while materialities are often overlooked and trivialized they are important for how daily life, identities, and agencies are shaped in the studied care settings.

Cleeve is concerned with exploring how research and visual communication can be brought into meaningful relationships with one another. Her article "Markings: Boundaries and Borders in Dementia Care Units" was written in the form of a visual essay where the visuals are not merely accessory to the text, but forms a crucial part of the argument. It was the first visual essay to be published in the journal Design and Culture. Cleeve has given several lectures on visual communication for researchers, and also works as a freelance illustrator. Among her illustration projects are brochures for patients undergoing cancer treatment, research communication materials, and an anthology for Sveriges Unga Akademi. 